\title{
Ensino da Física utilizando libreoffice calc
}

\author{
Argemiro M. Bastos ${ }^{1}$, Tales B. Marcello ${ }^{2}$ \\ ${ }^{1}$ Instituto Federal de Educação, Ciência e Tecnologia do Amapá (IFAP) - Campus \\ Macapá \\ argemiro.bastos@ifap.edu.br, tbmarcello.ap@gmail.com
}

\begin{abstract}
As an example of implementation of technology-supported teaching, an educational modeling project was developed to use LibreOffice Calc software like minimizer of learning disabilities and helper in the transfer information by the teacher. The project consisted in application of diagnostic questionnaires, at the Federal Institute of Amapá - Macapá campus in 2013, and further development of modeling activities, having as object the subjects of physics which have more difficulty of learning by students.
\end{abstract}

Resumo. Como exemplo de aplicação de ferramentas tecnológicas aplicadas ao ensino, foi desenvolvido um projeto de modelagem educativa que propõe o uso do software LibreOffice Calc como minimizador das dificuldades de aprendizagem e auxiliar no repasse de informações pelo professor. O projeto consistiu de aplicação de questionários diagnósticos, no Instituto Federal do Amapá - campus Macapá no ano de 2013, e posterior elaboração de atividades de modelagem, tendo como objeto os temas de Física que apresentam maior dificuldade de aprendizagem pelos alunos. 


\section{Introdução}

Ensinar Física não é uma tarefa fácil para o profissional da área. A aprendizagem em Física pressupõe análise de atividades cognitivas fundamentais como conceptualização, resolução de problemas e também compreensão de textos. Há então a necessidade de diversificar as ferramentas que auxiliem o aprendizado do aluno e concorram para a construção do conhecimento de forma plena. O sistema de ensino brasileiro tem experimentado, com a utilização do computador, um novo impulso de qualidade vista por muitos como uma revolução no meio educacional, atendendo a necessidade de utilizar novas ferramentas tecnológicas no ensino. Nesta perspectiva, o projeto de modelagem educativa vem lançar um novo olhar sobre esta questão. Utilizando o LibreOffice Calc (software livre), o trabalho propõe o desenvolvimento analítico de atividades de modelagem relacionadas aos conteúdos que apresentarem maior dificuldade de entendimento por parte dos alunos do Ensino Médio.

O uso do computador em uma simulação ou na modelagem matemática é uma possibilidade de transição dos modelos tradicionais de ensino para a construção de formas alternativas de ensinar Física. O LibreOffice Calc é um software livre similar ao Excel, destinado à criação de planilhas eletrônicas, ou seja, ao invés de trabalhar com números usando um lápis, uma folha de papel e uma calculadora, estes são digitados em uma tabela eletrônica onde é possível alterar e atualizá-los sempre que necessário [OLIVEIRA, 2012]. O software livre se apresenta como uma solução eficiente para este fato, além de se poder obtê-lo e utilizá-lo com custo acessível às escolas. Essas são algumas das formas com que o software livre tem contribuído no meio educacional. Sem contar a oportunidade de promover a inclusão digital e liberdade que este tem por natureza e que é sua essência [DA SILVEIRA, 2003].

O sucesso do ensino de Física depende da capacidade de o aluno aprender a aprender e a pensar, fazendo a ponte entre teoria e prática. Desta forma, ele estará apto a fundamentar a crítica e a argumentar com base em fatos. Neste sentido, o uso da modelagem é uma ferramenta que busca associar e correlacionar o que é previsto (teoria) e o que é observado (experiência). O uso de planilhas do LibreOffice Calc pode apresentar resultados numéricos das medidas realizadas ou propostas que ao serem confrontadas com a formulação teórica do fenômeno enriquecerão a interação dos alunos com os conceitos da Física de forma proveitosa do ponto de vista tanto didático como vivencial.

\section{Materiais e métodos}

O método dialético foi utilizado no desenvolvimento do trabalho, onde o problema proposto é analisado a partir da realidade vivenciada na sala de aula através das práticas pedagógicas utilizadas. Havendo contato direto do pesquisador com a situação estudada, verificou-se por meio de questionários a forma como está sendo discutida a base teórica e os fenômenos associados que possam ser utilizados com exemplos. 
O projeto foi desenvolvido com 81 alunos, no período de março/2013 a fevereiro/2014, nas turmas 1012-A Alimentos ( ${ }^{\mathrm{a}}$ série), 4022-A Mineração ( $2^{\mathrm{a}}$ série) e 1032-A Alimentos ( $3^{\mathrm{a}}$ série), turno vespertino, dos cursos integrados do Instituto Federal de Educação, Ciência e Tecnologia (IFAP). A escolha dos cursos deve-se a dois aspectos: primeiro porque o bolsista que desenvolveu o projeto estuda no turno da manhã; segundo, porque estes cursos têm apresentado alto índice de reprovação na componente Física em anos anteriores. As turmas escolhidas têm aula da componente Física em um mesmo dia, desta forma foi otimizado o deslocamento para aplicação de questionário e coleta de dados.

A partir da análise das dificuldades de aprendizagem relatadas pelos alunos, foram propostas 2 (duas) atividades de modelagem. As discussões sobre a precisão, aplicabilidade cotidiana e mudanças de variáveis foram confrontadas com a base científica que explica o problema. O objetivo deste procedimento é comprovar a lógica dos resultados obtidos e ao mesmo tempo observar a influência de fatores ausentes ou desprezados na execução da modelagem.

\section{Resultados e discussão}

A partir dos resultados fica visível que as turmas visitadas possuem uma baixa disponibilidade de equipamentos e materiais em sala de aula e pouco se utilizam de softwares como ferramentas educacionais, mesmo quando vão ao laboratório de informática. Acima de $70 \%$ dos alunos nas três turmas consideram importante a utilização de recursos tecnológicos na sala de aula, pois o uso de softwares facilita a aprendizagem. Segundo Liguori (1997), em um contexto em que os alunos têm abundante capital de conhecimentos, concepções ideológicas e preconcepções sobre os diferentes âmbitos da realidade, as instituições educacionais possuem o desafio não somente de incorporar as novas tecnologias da informação como conteúdos de ensino, mas também de elaborar, desenvolver e avaliar práticas pedagógicas que promova o desenvolvimento sobre os conhecimentos e os usos tecnológicos.

Quanto às dificuldades dos alunos na aprendizagem da Física, destacam-se a falta de concentração e a falta de interpretação, fatores esses que podem ter sido originados por conta de um ensino que pouco atraí a atenção dos alunos e não desperta interesse nos mesmos, dificultando o entendimento e concentração nas aulas. Uma solução para isso seria a aplicação de atividades de um modo mais lúdico, fazendo com que o aluno tenha mais interação com o assunto estudado, algo que poderia ser feito com o auxílio de ferramentas tecnológicas, como a proposta por este trabalho, qual seja a utilização do software LibreOffice Calc na facilitação do entendimento da Física e aplicação dos seus conceitos: “Aprender precisa ser uma atividade interessante (...) uma ótima maneira para tornar o aprendizado uma experiência divertida é investir na tecnologia" [ABÉLLON, 2013].

\section{Construção das atividades de modelagem educativa}

Os temas reportados como de maior dificuldade de compreensão por parte dos alunos da turma de $1^{\mathrm{a}}$ série 1011-A foi gravitação universal, e nas turmas de $2^{\mathrm{a}}$ e $3^{\mathrm{a}}$ série, por estarem estudando o mesmo assunto, foi óptica geométrica. Identificando essas dificuldades e o interesse dos alunos no uso de ferramentas tecnológicas para seu 
aprendizado, foram confeccionadas duas atividades de modelagem educativa nomeadas como Gravitação Universal e Óptica Geométrica utilizando o software proposto pelo projeto, LibreOffice Calc.

Como forma de organizar e tornar as atividades mais intuitivas, cada arquivo criado no Calc foi divido em 04 (quatro) planilhas: Abertura, Teoria, Prática e Bibliografia. A figura 1 apresenta as planilhas de abertura das atividades de modelagem Gravitação Universal e Óptica Geométrica, contendo figuras referentes ao assunto, o título do projeto destacado na barra superior, um cabeçalho com informações a respeito do autor, e logo abaixo no quadrado verde no centro, esta o título da atividade e um sumário com hiperlinks que levam às demais planilhas. Como alternativa de navegação, na parte inferior encontra-se um hiperlink com a inscrição próxima, possibilitando a navegação para segunda planilha.
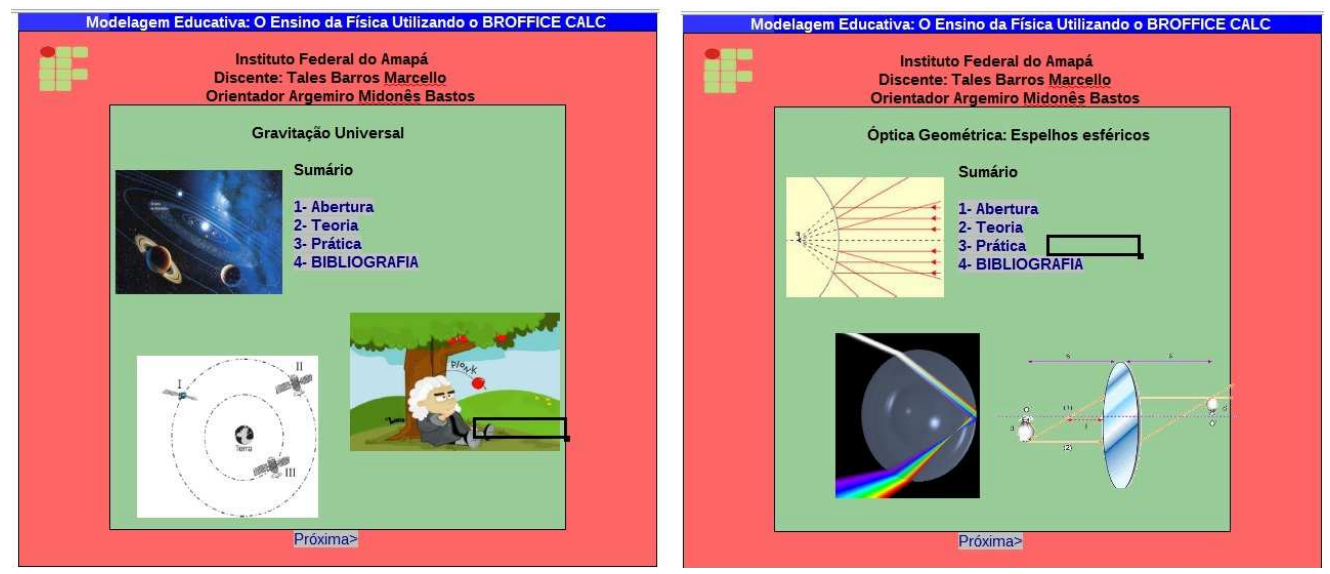

Figura 1 - planilhas de abertura das atividades de modelagem Gravitação Universal e Óptica Geométrica.

Na Figura 2 é possível visualizar os ambientes fornecidos pela planilha 2 (dois), que tratam da parte teórica das atividades, nesta planilha são descritas as propriedades físicas e teóricas dos assuntos tratados, possuindo nas mesmas fórmulas e imagens para representação e exemplificação dos conceitos físicos fornecidos.
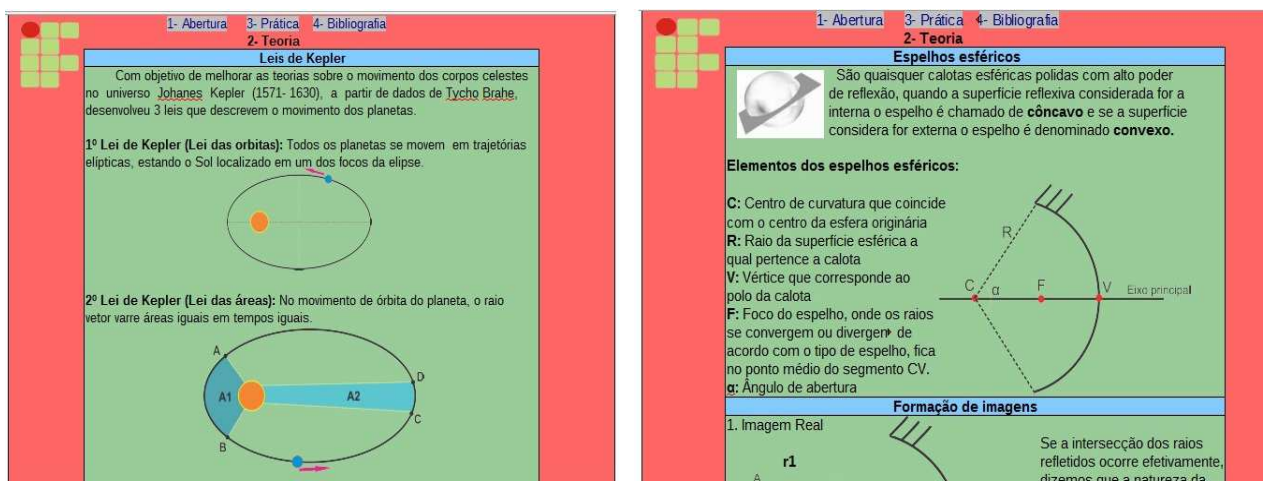

Figura 2 - Planilha 2 das atividades de modelagem Gravitação Universal e Óptica Geométrica.

$\mathrm{Na}$ figura 3 estão representadas as planilhas que envolvem a aplicação da teoria vista na planilha de número 2 , por meio de simulações ocorridas com a inserção de valores pelo usuário, a planilha do lado esquerdo da figura refere-se à planilha prática da atividade voltada para Gravitação Universal, e a planilha do lado direito à atividade envolvendo Óptica Geométrica. 

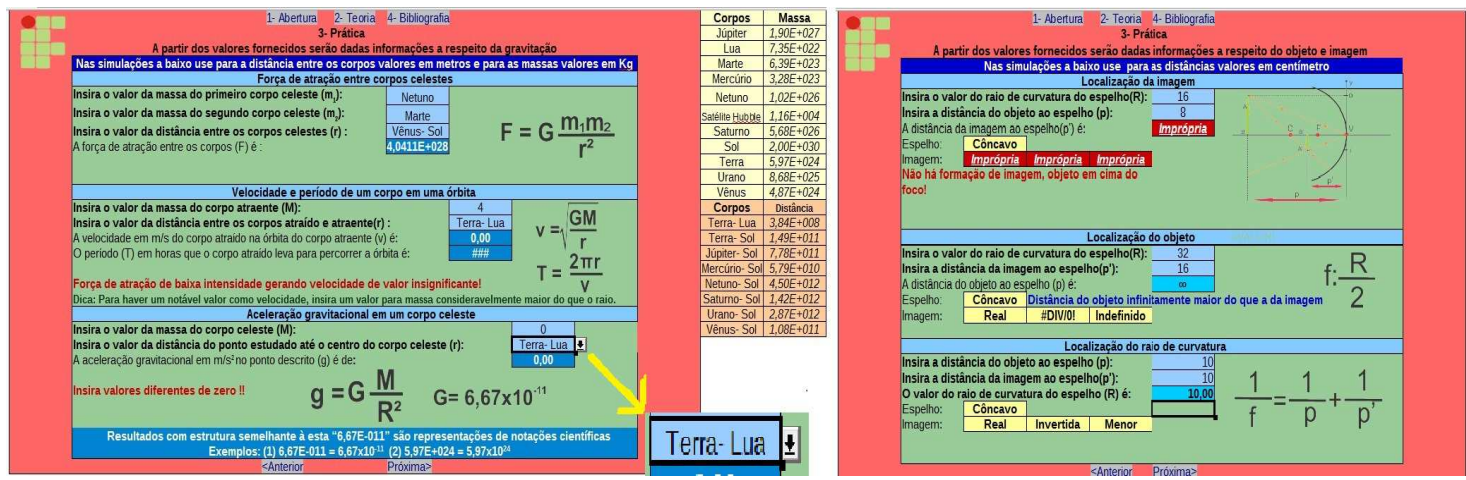

Figura 3 - Planilha 3 das atividades de modelagem Gravitação Universal e Óptica Geométrica.

As duas atividades possuem três simulações cada, na planilha da esquerda as simulações dizem respeito à obtenção da força de atração entre dois corpos celestes, velocidade e período de um corpo em determinada órbita e aceleração gravitacional na superfície de um corpo, cada simulação contém ao lado as fórmulas físicas que estão sendo usadas no LibreOffice Calc para calcular o desejado, assim o usuário pode verificar manualmente e conferir se o que ele fez esta correto ou precisa ser refeito.

\section{Construção das atividades de modelagem educativa}

Sabendo que os alunos têm interesse no aprendizado por meio de recursos tecnológicos, e que é presente a dificuldade no entendimento da Física por conta da realização de cálculos matemáticos, se faz necessário a busca por meios tecnológicos que sanem essas dificuldades e correlacionem os conteúdos das disciplinas. O LibreOffice Calc pode ser utilizado para minimizar as dificuldades de aprendizagem dos alunos, pois além de ser um software livre possui fácil uso e manipulação. Os alunos visualizando modelos que podem ser apresentados e se familiarizando com o programa aos poucos construirão seus próprios modelos para solução de problemas. Esperamos que ações como esta possam fomentar o uso desses recursos em diferentes componentes curriculares.

\section{Referências}

ABÉLLON, Marcos. Educando através da tecnologia. Disponível no endereço eletrônico:

<http://www.q21.com.br/questions_to_learn_educando_atraves_da_tecnologia.html >. Acessado dia 15 de dez. de 2013 às 14 horas e 57 minutos.

DA SILVEIRA, Sérgio Amadeu. Inclusão digital, software livre e globalização contra hegemônica. In: Software Livre e Inclusão Digital. Organizadores: Sergio Amadeu de Silveira e Joao Cassino, São Paulo: Conrad 7, 2003.

LIGUORI, Laura M. As Novas Tecnologias da Informação e da Comunicação no Campo dos Velhos Problemas e Desafios Educacionais. In: Tecnologia educacional: política, histórias e propostas. Porto Alegre, RS: Artes Médicas, 1997.

OLIVEIRA, Elvis. O Software Livre dos Brasileiros: BrOffice.org. Anais do Congresso Nacional Universidade, EAD e Software Livre. Vol. 1. No. 1. 2012. 